\title{
Cross-Cultural Comparison of Genetic and Cultural Transmission of Smoking Initiation Using an Extended Twin Kinship Model
}

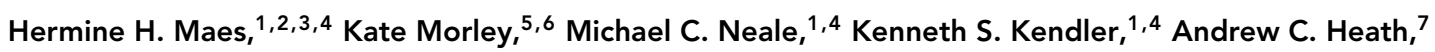 \\ Lindon J. Eaves, ${ }^{1,4}$ and Nicholas G. Martin ${ }^{5}$ \\ ${ }^{1}$ Department of Human Genetics, Virginia Institute for Psychiatric and Behavioral Genetics, Virginia Commonwealth \\ University, Richmond, VA, USA \\ ${ }^{2}$ Massey Cancer Center, Virginia Commonwealth University, Richmond, VA, USA \\ ${ }^{3}$ Faculty of Kinesiology and Rehabilitation Sciences, Katholieke Universiteit Leuven, Leuven, Belgium \\ ${ }^{4}$ Department of Psychiatry, Virginia Institute for Psychiatric and Behavioral Genetics, Virginia Commonwealth University, \\ Richmond, VA, USA \\ ${ }^{5}$ Genetic Epidemiology, QIMR Berghofer Medical Research Institute, Brisbane, Queensland, Australia \\ ${ }^{6}$ Social, Genetic \& Developmental Psychiatry Centre, Institute of Psychiatry, London, UK \\ ${ }^{7}$ Department of Psychiatry, Washington University School of Medicine, St Louis, MO, USA
}

\begin{abstract}
Background: Considerable evidence from twin and adoption studies indicates that genetic and shared environmental factors play a role in the initiation of smoking behavior. Although twin and adoption designs are powerful to detect genetic and environmental influences, they do not provide information on the processes of assortative mating and parent-offspring transmission and their contribution to the variability explained by genetic and/or environmental factors. Methods: We examined the role of genetic and environmental factors in individual differences for smoking initiation (SI) using an extended kinship design. This design allows the simultaneous testing of additive and non-additive genetic, shared and individual-specific environmental factors, as well as sex differences in the expression of genes and environment in the presence of assortative mating and combined genetic and cultural transmission, while also estimating the regression of the prevalence of SI on age. A dichotomous lifetime 'ever' smoking measure was obtained from twins and relatives in the 'Virginia 30,000' sample and the 'Australian 25,000'. Results: Results demonstrate that both genetic and environmental factors play a significant role in the liability to SI. Major influences on individual differences appeared to be additive genetic and unique environmental effects, with smaller contributions from assortative mating, shared sibling environment, twin environment, cultural transmission, and resulting genotype-environment covariance. Age regression of the prevalence of SI was significant. The finding of negative cultural transmission without dominance led us to investigate more closely two possible mechanisms for the lower parent-offspring correlations compared to the sibling and DZ twin correlations in subsets of the data: (1) age $\times$ gene interaction, and (2) social homogamy. Neither of the mechanism provided a significantly better explanation of the data. Conclusions: This study showed significant heritability, partly due to assortment, and significant effects of primarily non-parental shared environment on liability to SI.
\end{abstract}

Keywords: smoking initiation (SI), extended twin kinship design, genetics, assortment, cultural transmission

Smoking remains a serious public health problem. Briefly, tobacco is the second major cause of death in the world, killing seven million people each year (World Health Organization, 2018). In the United States, cigarettes are estimated to be responsible for a third of all cancer deaths ( $>85 \%$ of lung cancer deaths) and a third of deaths from cardiovascular disease (U.S. Department of Health and Human Services, 2010). In Australia, tobacco smoking increases the risk of cardiovascular disease incidence by
RECEIVED 8 March 2018; ACCEPTED 4 April 2018

AdDress for Correspondence: Dr. Hermine H. Maes, Department of Human Genetics, Virginia Institute for Psychiatric and Behavioral Genetics, Virginia Commonwealth University, PO Box 980033, Richmond, VA 23298-0033, USA. E-mail:hmaes@vcu.edu 
between two- and four-fold (Scollo \& Winstanley, 2015). Smoking harms nearly every organ in the body, causing many diseases and reducing health in general (U.S. Department of Health and Human Services, 2010). The economic costs of tobacco use are equally devastating.

Considerable evidence exists that genetic and environmental factors play a significant role in the liability to smoking initiation (SI) (see Maes \& Neale, 2009, for a review). Other reviews of this literature have been published by Sullivan and Kendler (1997), Heath et al. (1998), Li (2003), and Kaprio (2009). The evidence primarily stems from twin and adoption studies. In summary, of the more than 15 published adult twin studies of lifetime or current use of tobacco products (which we will term SI), originating from seven different countries, estimates of the heritability $\left(h^{2}\right)$ of SI were generally high, with most values falling between $40 \%$ and $70 \%(\mathrm{Mdn}=57 \%)$. The unweighted mean $( \pm S D)$ estimate of $h^{2}$ for the 26 adult samples (males and females considered separately) was $0.56 \pm .14$. Estimates of the proportion of variance in liability due to shared environmental effects $\left(c^{2}\right)$ were more variable, with most ranging from $0 \%$ to $50 \%$, and the unweighted mean $( \pm S D)$ estimate was $0.22 \pm .18$. The unweighted mean estimate for individual-specific environmental effects $\left(e^{2}\right)$ was 0.22 ( \pm .13$)$. These conclusions are also supported by studies of twins reared apart and adoption studies of smoking (Eaves \& Eysenck, 1980, Kendler et al., 2000). Two studies compared heritability estimates across a range of ages/birth cohorts, gender, and cultures (Australia, Sweden and Finland: Madden et al., 2004; United States and Australia: Heath et al., 1993). While the early study found some significant differences in heritability across cultures, the second reported remarkable consistency of estimates. To our knowledge, no other study including twins and other relatives has undertaken a cross-cultural comparison of average smoking habits and the role of genes and environment in individual differences.

Although a number of studies have reported associations between the SI of parents and that of their children, these studies typically are not informative about the relative contributions of genes and environment. One study used a twin-parent model for smoking to estimate the degree of assortment and the role of genetic versus cultural transmission (Boomsma et al., 1994). They found that the correlation between spouses for 'ever smoked' was rather low $(0.18)$ and that the parent-offspring resemblance could be accounted for completely by their genetic relatedness. Another study included correlations for twins and their parents (including a spousal correlation of 0.42) but did not model them explicitly (Kaprio et al., 1995). An earlier report on analyses of the Virginia 30,000 sample used the extended twin (ET) kinship model (Maes et al., 2006) to analyze data collected on twins, their spouses, and first-degree relatives. This ET design allows the simultaneous testing of additive and non-additive genetic, shared and individual- specific environmental factors, as well as sex differences in the expression of genes and environment in the presence of assortative mating and combined genetic and cultural transmission.

In this paper, we will attempt to replicate these results using an ET design in a comparably large sample from Australia, and compare the role of genetic and environmental factors for SI with those in the Virginia sample. First, we estimated the correlations between relatives and consider their overall pattern across the different types of relative. Second, we fit a model to the data for the purpose of formal hypothesis testing. These analyses are undertaken for both the U.S. and Australian sample separately, as well as for the combined sample, to test the equality of the estimates across samples.

\section{Materials and Methods}

The data used in this study come from two large epidemiological samples: the United States sample comprises 25,861 respondents and the Australian sample comprises 24,457 respondents who completed a self-report mailed questionnaire and answered questions about smoking behavior. Both samples are based on twins, and include their spouses and their first-degree relatives (i.e., parents, siblings, and offspring). Within the ET family structure in this study there are 88 unique sex-specific biological and social relationships. Zygosity of twins was determined on the basis of responses to standard questions about similarity and the degree to which others confused them in both samples. This method has been shown to give at least $95 \%$ agreement with diagnosis based on extensive blood typing (Eaves et al., 1989; Martin \& Martin, 1975; Ooki et al., 1990).

\section{The 'Virginia 30,000'}

The Virginia sample contains data from 14,763 twins, ascertained from two sources (Eaves et al., 1999; Truett et al., 1994). Public birth records and other public records in the Commonwealth of Virginia were used to obtain current address information for twins born in Virginia between 1915 and 1971, with questionnaires mailed to twins who had returned at least one questionnaire in previous surveys. A second group of twins was identified through their response to a letter published in the newsletter of the American Association of Retired Persons (AARP, 9,476 individuals). Twins participating in the study were mailed a 16-page 'Health and Lifestyles' questionnaire and asked to supply the names and addresses of their spouses, siblings, parents, and children for the follow-up study of relatives of twins. Completed questionnaires were obtained from $69.8 \%$ of twins invited to participate in the study, which was carried out between 1986 and 1989. The original twin questionnaire was modified slightly to provide two additional forms, one appropriate for the parents of twins and another for the spouses, children, and siblings of twins. 


\begin{tabular}{|c|c|c|c|c|c|c|c|c|c|}
\hline \multicolumn{9}{|c|}{$\begin{array}{l}\text { TABLE } 1 \\
\text { Age-Adjus }\end{array}$} & of \\
\hline \multirow[b]{2}{*}{ Males } & \multicolumn{3}{|c|}{ Twins } & \multicolumn{3}{|c|}{ Husbands } & \multirow[b]{2}{*}{ Fathers } & \multirow[b]{2}{*}{ Brothers } & \multirow[b]{2}{*}{ Sons } \\
\hline & $M Z$ & $\mathrm{DZ}$ & DZO & $\mathrm{MZ}$ & $\mathrm{DZ}$ & DZO & & & \\
\hline U.S. & 0.52 & 0.52 & 0.58 & 0.56 & 0.60 & 0.53 & 0.72 & 0.55 & 0.50 \\
\hline$N$ & 1,593 & 1,189 & 1,370 & 2,076 & 1,343 & 376 & 781 & 1,021 & 1,607 \\
\hline Australia & 0.50 & 0.54 & 0.52 & 0.62 & 0.60 & 0.60 & 0.71 & 0.60 & 0.44 \\
\hline \multirow[t]{2}{*}{$N$} & 1,671 & 1,188 & 1,298 & 1,979 & 1,282 & 230 & 1,417 & 1,479 & 643 \\
\hline & \multicolumn{3}{|c|}{ Twins } & \multicolumn{3}{|c|}{ Wives } & & & \\
\hline Females & $\mathrm{MZ}$ & DZ & DZO & MZ & $\mathrm{DZ}$ & $\overline{D Z O}$ & Mothers & Sisters & Daughters \\
\hline U.S. & 0.42 & 0.45 & 0.44 & 0.38 & 0.43 & 0.53 & 0.47 & 0.47 & 0.51 \\
\hline$N$ & 3,801 & 2433 & 1,350 & 635 & 718 & 469 & 1,182 & 1,527 & 2,390 \\
\hline Australia & 0.45 & 0.50 & 0.59 & 0.43 & 0.39 & 0.47 & 0.37 & 0.45 & 0.46 \\
\hline$N$ & 3,176 & 2,080 & 1,247 & 1,094 & 732 & 254 & 1,893 & 1,909 & 885 \\
\hline
\end{tabular}

Modifications affected only those aspects of the questionnaire related to twinning. The response rate from relatives $(44.7 \%)$ was much lower than that from the twins. Of the complete sample of 28,492 individuals (from 8,567 extended kinships), $58 \%$ were female, with $50 \%$ of respondents under 50 years of age.

\section{The 'Australian 25,000'}

The Australian sample was ascertained through two cohorts of twins. The first cohort was recruited in 1980-82 from a sampling frame that comprised 5,967 twin pairs aged 18 years or older (born 1893-1964) then enrolled in the Australian Twin Registry (ATR). Responses were obtained from 3,808 complete pairs (64\%; Jardine et al., 1984) and these were followed up with a second mailed questionnaire in 1988-90 with responses from 2,708 complete pairs (Heath et al., 1994) and 337 incomplete pairs (81\% of those still contactable). In this follow-up questionnaire, twins were asked to provide the names of parents, siblings, spouses, and children who would be prepared to answer similar mailed questionnaires. The second cohort of twins, born 1964-71, were recruited from the ATR in 1989 and were mailed similar questionnaires in 1989-91, with responses from 3,769 individuals from 4,269 eligible pairs. This cohort was also asked to provide names of relatives who were prepared to fill in questionnaires. In total, names of 14,421 relatives were provided for Cohort 1, and 4,999 names for Cohort 2. A suitably modified version of the questionnaire was prepared for parents, and another version for siblings, spouses, and children of twins. These were mailed out during the period 1989-91 and, respectively, 8,601 (60\%) and 2,799 (56\%) of relatives from Cohorts 1 and 2 returned questionnaires (response rates varied with type of relative, from $65 \%$ for mothers to $56 \%$ for siblings). There was vigorous follow-up of non-responding twins (up to five phone calls) but somewhat less assiduous follow-up of relatives (up to two phone calls).

Table 1 breaks down the sample sizes for SI by type of relative and sex, as well as by zygosity for the twins only.
There are some differences in the breakdown between the two samples. The United States sample has proportionally fewer parents and siblings and more spouses and offspring than the Australian sample, probably reflecting the older age of the U.S. sample.

\section{Measures}

Participants in both studies completed a questionnaire covering a range of health and lifestyle issues and including almost identical questions about their smoking behavior. Self-report data on smoking were obtained from three items. Respondents were asked to indicate the number corresponding to the frequency that best described their smoking habits during their lifetime. The four possible response values were: never smoked, used to smoke but gave it up, smoked on and off, smoked most of your life. Smoking quantity was measured as the number that expressed their best estimate of the DAILY cigarette consumption (or equivalent in pipefuls or cigars) during their lifetime, with six response categories: never, 1-5 per day, 5-10 per day, 11-20 per day, 21-40 per day, and $>40$ per day. Age of onset was recorded as the age at which they started smoking. Based on these three variables, we created a dichotomous variable, 'smoking initiation', reflecting whether they had ever smoked or not. If they responded 'never smoked' to the smoking frequency question and 'never' to the smoking quantity question and did not report an age of onset for smoking, they were coded zero on the dichotomous smoking variable. If on the other hand, they reported any of the other three response categories for smoking frequency OR any of the other five categories for smoking quantity OR an age of onset, they were coded 1 . Responses were consistent across the three variables for $>85 \%$ of the sample. About $10 \%$ of the sample was coded a smoker based on two out of three variables. In less than $1 \%$ of the sample was someone coded a smoker on the basis of only one of these three variables. Another $\sim 1 \%$ were assigned missing values for the dichotomous smoking variable. 


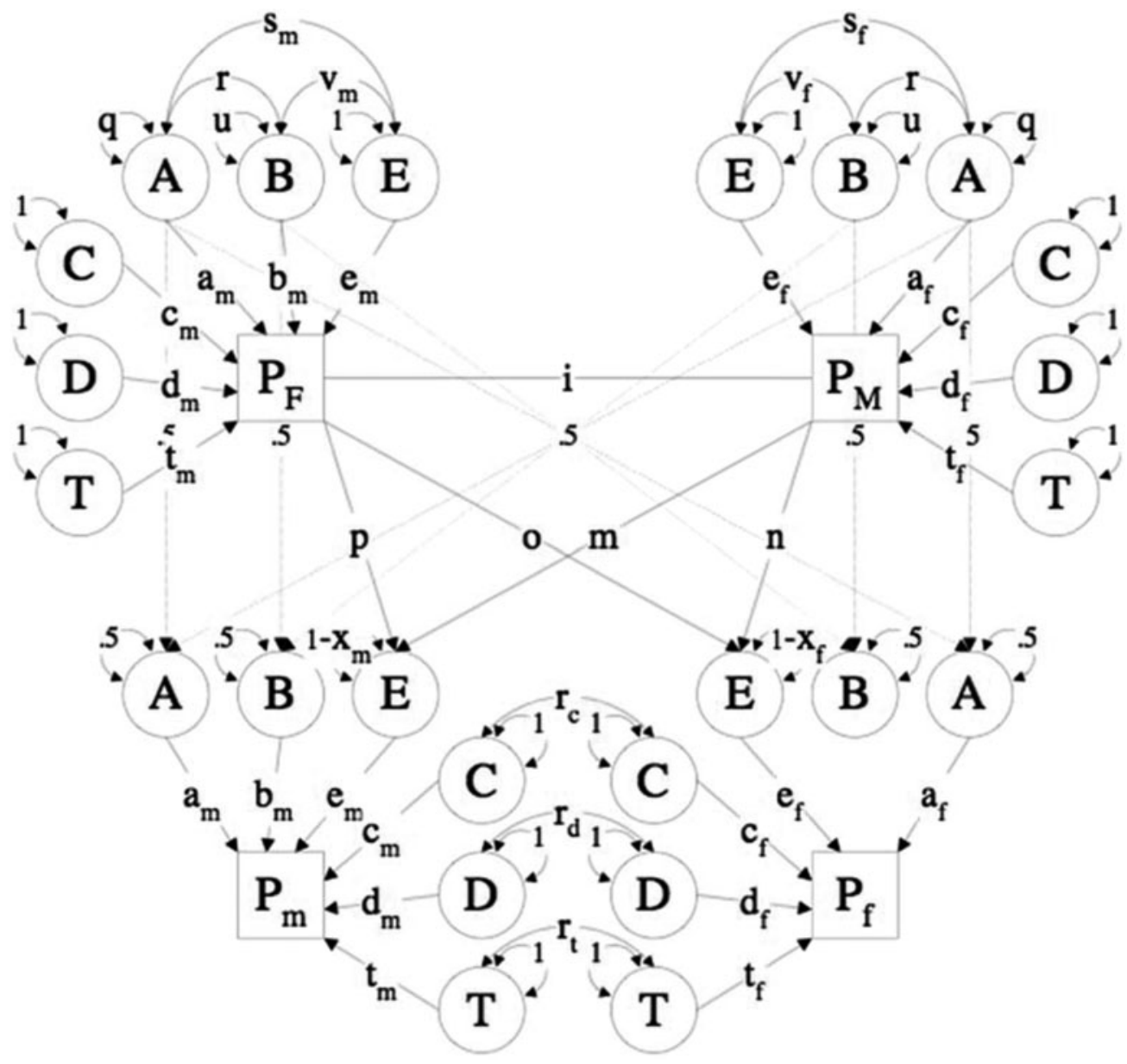

\section{FIGURE 1}

Full extended family resemblance model for opposite-sex DZ twins and their parents. Path coefficients are the same in both generations, and gene-gene and gene-environment correlations occur in both generations (dominance, shared environment, and twin environment not shown for the parental generation). Note: af = gender-common additive genes-females, am = gender-common additive genes-males, $b$ = male-specific additive genes-males, $r=$ induced correlation between gender-common and male-specific additive genetic effects, $\mathrm{df}=$ non-additive genes-females, $\mathrm{dm}=$ non-additive genetic parameter-males, $\mathrm{rd}=$ correlation between male and female non-additive genetic effects, $\mathrm{cf}=$ common environment-females, $\mathrm{cm}=$ common environment parameter-males, $\mathrm{rc}=\mathrm{correlation}$ between male and female common environment, $\mathrm{tf}=$ special twin environment-females, $\mathrm{tm}=$ special twin environment parameter-males, $\mathrm{rt}=$ correlation between male and female special twin environmental effects, $n=$ maternal cultural transmission - females, $m=$ maternal cultural transmission-males, $o=$ paternal cultural transmission-females, $p=$ paternal cultural transmission-males, ef $=s p e c i f i c$ environment parameter-females, em $=$ specific environment parameter-males, $i=$ assortative mating parameter, sf $=$ correlation between gender-common additive genetic effects and environment-females, $\mathbf{s m}=$ correlation between gender-common additive genetic effects and environment-males, $\mathrm{vf}=$ correlation between male-specific additive genetic effects and environment-females, vm $=$ correlation between male-specific additive genetic effects and environment-males.

\section{Statistical Methods}

Structural modeling of the data was undertaken using methods described in Eaves et al. (1999), Truett et al. (1994) and Lake et al. (2000), which assess the contributions of genetic and environmental effects in the presence of assortative mating. The ET model, which is an extension of the ACE model (Neale \& Cardon, 1992) is described in more detail in Maes et al. (2006). Briefly, genetic effects can be either (1) additive or (2) dominant. Besides unique environmental factors, three sources of shared environmental influences can be distinguished: (1) shared (sibling) environment, (2) twin environment, and (3) cultural transmis- sion. The latter is modeled as vertical cultural transmission from parent to child, and reflects the non-genetic impact of the parent's phenotype on the environment of their children. The correlation between spouses is assumed to result from phenotypic assortment, which occurs when mate selection is based at least partly on the trait being studied. The contribution of the genetic and environmental factors may be dependent upon sex, both in their magnitude and nature. Figure 1 presents a path diagram of the ET model. Note that only two generations are shown, as all the model parameters can be depicted with drawing just an opposite-sex pair of twins and their parents. The model was implemented in 


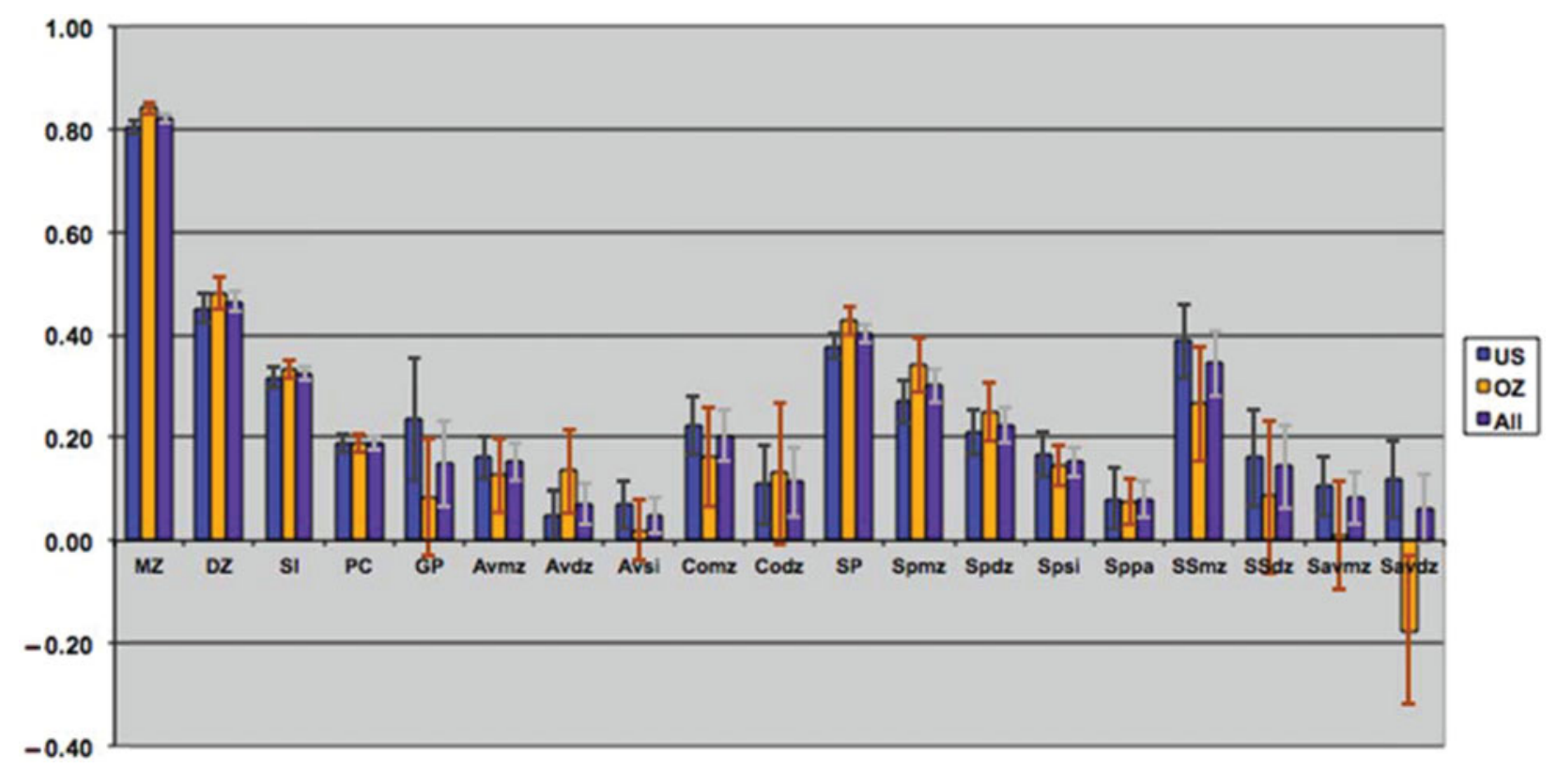

\section{FIGURE 2}

(Colour online) Maximum likelihood correlations for smoking initiation in the VA30,000 and OZ25k, grouped by degree of genetic and environmental similarity, constrained to be equal across sex.

the statistical modeling package Mx (Neale et al., 2006) and OpenMx (Boker et al., 2010; Neale et al., 2017) and fit to the raw ordinal data to obtain maximum likelihood estimates of the model parameters, allowing the inclusion of covariates such as age to the model. We included age regression on the thresholds by sex based on results from prior analyses of the U.S. sample (Maes et al., 2006). As a result of the additional complexity of the model, we opted to include a maximum of two siblings and children of twins, leading to a minor reduction of the total sample size by about $1 \%$. A detailed description of the Mx specification of the ET model is given in Maes et al. (1999).

Prior to the fitting the ET model to the data of the two samples, the thresholds for each of the relatives and the correlations for the 88 sex-specific relationships were estimated in OpenMx by maximum likelihood. Using this approach, we obtain unbiased estimates of the parameters if missing observations are missing at random (Little \& $\mathrm{Ru}$ bin, 1987). We evaluated whether the thresholds could be equated across twin order, generation, and gender. Furthermore, we tested gender heterogeneity of the correlations within each category of social and biological relatedness, both separately and combined. OpenMx scripts are available upon request.

\section{Results}

\section{Response Frequencies}

Prevalence rates for SI are presented in Table 1, by sex, country, and type of relative. We systematically tested the equality of thresholds across twin order, zygosity, genera- tion, sex, and country, while allowing age as a covariate. Prevalence rates for the two members of twin pairs, for the spouses of the two twins, and the children of twins could be equated within each sample, as could rates for first-degree relatives (e.g., fathers and brothers) across zygosity. However, rates could not be equated for twins and spouses across zygosity, or for relatives within generations (twins, spouses, and siblings) or across generations (parents, twins, and children of twins) without significant loss of fit (results not shown). Furthermore, prevalence rates were significantly different between the two samples, but not consistently in one direction. This might be due to the relatively large sample sizes to test for threshold (mean) differences. However, the marked difference between SI of men and women was consistent with higher prevalence rates in men for all types of relative except the children of twins. Finally, a decrease in prevalence of SI over three generations (fathers vs. twins/husbands/brothers vs. sons) was apparent for males, but not females, consistent with reported epidemiological trends for SI in males and females.

\section{Maximum Likelihood Estimation of Thresholds and Cor- relations}

Tetrachoric correlations for all the 88 sex-specific relationships were estimated by maximum likelihood, properly accounting for the dependency of the observations of relatives. Figure 2 shows the maximum likelihood estimates of the tetrachoric correlations separately for each sample, as well as a combined estimate by equating the 
TABLE 2

Comparision of FIML Correlations for Smoking Initiation in the U.S. and Australian Samples

\begin{tabular}{|c|c|c|c|c|c|c|c|}
\hline & \multirow[b]{2}{*}{$d f$} & \multicolumn{2}{|c|}{ U.S. } & \multicolumn{2}{|c|}{ Australian } & \multicolumn{2}{|c|}{ All } \\
\hline & & $x^{2}$ & $p$ & $x^{2}$ & $p$ & $x^{2}$ & $p$ \\
\hline Equate parent-offspring & 3 & 19.13 & 0 & 51.11 & 0 & 17.20 & 0 \\
\hline Equate twin-parent in law & 3 & 1.92 & .59 & 50.44 & 0 & 4.24 & .24 \\
\hline Equate siblings & 2 & 28.69 & 0 & 40.08 & 0 & 89.63 & 0 \\
\hline Equate sibs and spouse of twin & 3 & 1.54 & .67 & 4.02 & .26 & 4.85 & .18 \\
\hline Equate grandparents-children & 7 & 1.83 & .97 & 6.40 & .49 & 6.59 & .47 \\
\hline Equate avuncular through $\mathrm{MZ}$ twins & 3 & 4.81 & .19 & 53.63 & 0 & 3.99 & .26 \\
\hline Equate avuncular through DZ twins & 7 & 49.27 & 0 & 3.73 & .81 & 8.40 & .30 \\
\hline Equate avuncular through sibs & 7 & 6.27 & .51 & 10.15 & .18 & 12.60 & .08 \\
\hline Equate avuncular inlaws through $\mathrm{MZ}$ twins & 3 & 3.19 & .36 & -5.22 & & 1.69 & .64 \\
\hline Equate avuncular inlaws through DZ twins & 7 & 3.82 & .80 & 4.60 & .71 & 2.82 & .90 \\
\hline Equate cousins through $\mathrm{MZ}$ twins & 5 & 1.25 & .94 & 7.85 & .17 & 3.47 & .63 \\
\hline Equate cousins through DZ twins & 9 & 7.48 & .59 & 7.10 & .63 & 10.47 & .31 \\
\hline Equate spouse with $\mathrm{MZ}$ co-twin & 1 & 2.07 & .15 & -0.09 & & 1.45 & .23 \\
\hline Equate spouse with DZ co-twin & 3 & 0.78 & .86 & 3.51 & .32 & 2.24 & .52 \\
\hline Equate spouse with spouse $\mathrm{MZ}$ twin & 1 & 2.85 & .09 & 1.84 & .17 & 5.87 & .02 \\
\hline Equate spouse with spouse DZ twin & 2 & 2.61 & .27 & 0.34 & .85 & 2.73 & .26 \\
\hline Equate $\mathrm{MZ}$ twins & 1 & 1.16 & .28 & 2.00 & .16 & 0.12 & .73 \\
\hline Equate DZ twins & 2 & 16.48 & 0 & 11.57 & 0 & 27.65 & 0 \\
\hline Equate all correlations by sex & 69 & 107.13 & 0 & 97.48 & .01 & 151.38 & 0 \\
\hline
\end{tabular}

Note: Bold type indicates significant difference in correlations by sex.

correlations within category of biological/social relationship across sample. Confidence intervals were obtained by calculating the standard errors of the $z$-transformed values. The respective 88 correlations could be constrained across the two samples (-2LL for United States $=30,022.48$; for Australia $=26,997.31$; and United States $=$ Australia $=57,090.71)$ without loss of fit $\left(\chi_{88}^{2}=70.92, p=.91\right)$ when allowing the thresholds to differ by sample, which is remarkable given the power associated with the large sample sizes. In the combined analyses, 4 out of 18 gender heterogeneity tests were significant, including the parentoffspring pairs, siblings, and DZ twins (see Table 2). This appeared to be primarily driven by lower correlations between opposite-sex pairings than between same-sex pairings, which could be indicative of sex limitation. Note that these were the categories with the largest number of pairs of relatives.

The observed pattern of correlations for SI was consistent with additive genetic influences, with no evidence for dominance effects. The correlations further suggested small contributions of non-parental shared environmental factors and, possibly, special twin environment, due to the elevated DZ correlation compared to the sibling correlation. There was no evidence for cultural transmission; on the contrary, the pattern of correlations might be more consistent with negative cultural transmission because parent-offspring correlations were smaller (rather than greater) than might be expected from genetic factors alone. The spousal correlation for SI was highly significant, suggesting some form of assortment. The pattern of correlations through marriage observed for SI was consistent with both a genetic contribution to SI and assortative mating.

\section{Maximum Likelihood Estimation of Genetic and Envi- ronmental Contributions}

We fitted the full ET model first, separately to each of the samples (United States and Australia) and then to both samples simultaneously, constraining the genetic and environmental parameters across the samples while allowing the thresholds to differ between the samples. The minus twice the log-likelihood of the data was 30107.73 for the U.S. sample, 27072.37 for the Australian sample, and 57195.25 for the combined analyses, indicating a non-significant result for the cross-cultural comparison $\left(\chi_{29}^{2}=15.15, p=.98\right)$.

The full ET model allows for both qualitative (different factors in males and females, also referred to as non-scalar sex limitation) and quantitative (different magnitude of effects in males and females, also referred to as scalar sex limitation) sex differences of all the sources of variance. Although separately none of the individual tests for qualitative sex differences in variance components were significant (additive genetic, dominance genetic, shared environment, twin environment, and cultural transmission between opposite sexes from father or mother) the combined test was just significant $\left(\chi_{6}^{2}=13.4, p=.04\right)$. Similarly, none of the individual tests for quantitative sex differences was significant, nor was the combined test for all the genetic parameters or all the environmental parameters when allowing qualitative sex differences. However, some of these tests became significant after eliminating all qualitative sex differences, except cultural transmission sex differences). The overall test for sex differences in genetic and environmental parameters was highly significant $\left(\chi_{12}^{2}=80.6, p=.00\right)$.

This set of results suggested that the model might be overparameterized with highly correlated parameters. Eliminating whole sets of parameters (i.e., male and 


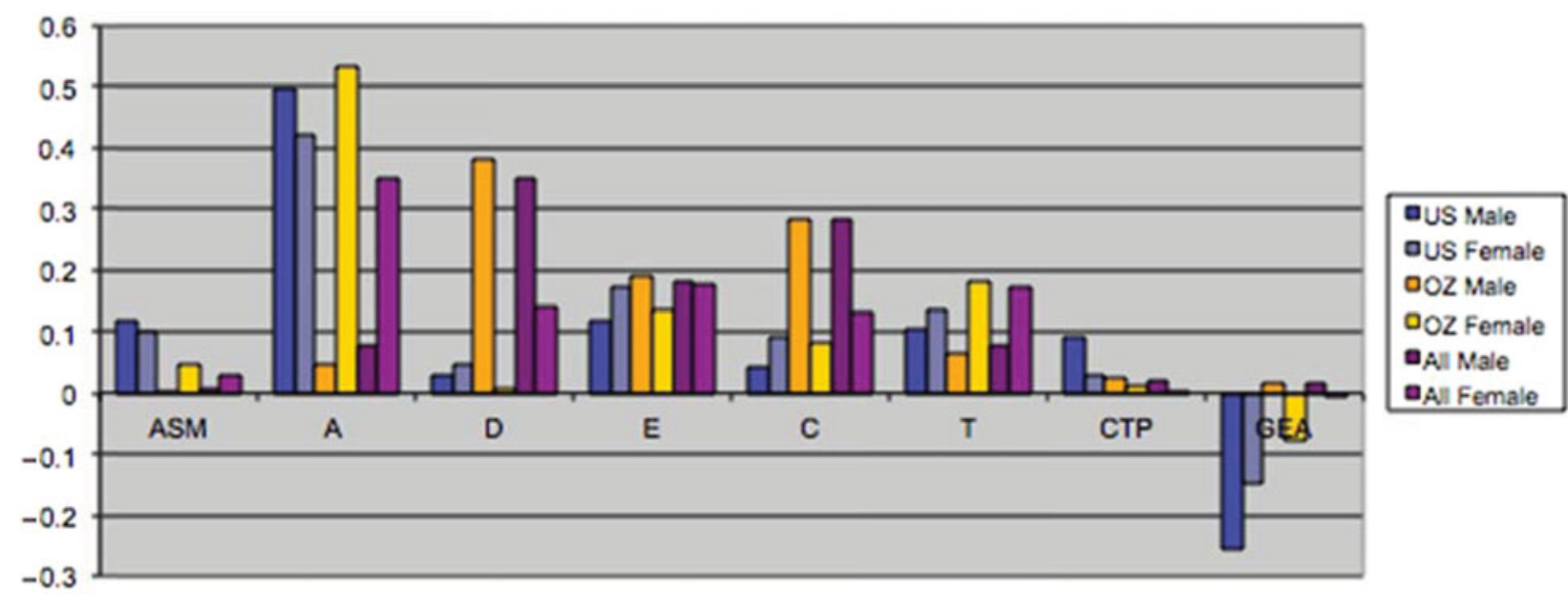

\section{FIGURE 3}

(Colour online) (a) Maximum likelihood estimates of parameters for the full extended family resemblance model for smoking initiation in the VA30,000 and OZ25k. (b) Maximum likelihood estimates of parameters for the extended family resemblance model for smoking initiation in the VA30,000 and OZ25k, not estimating dominance variance.

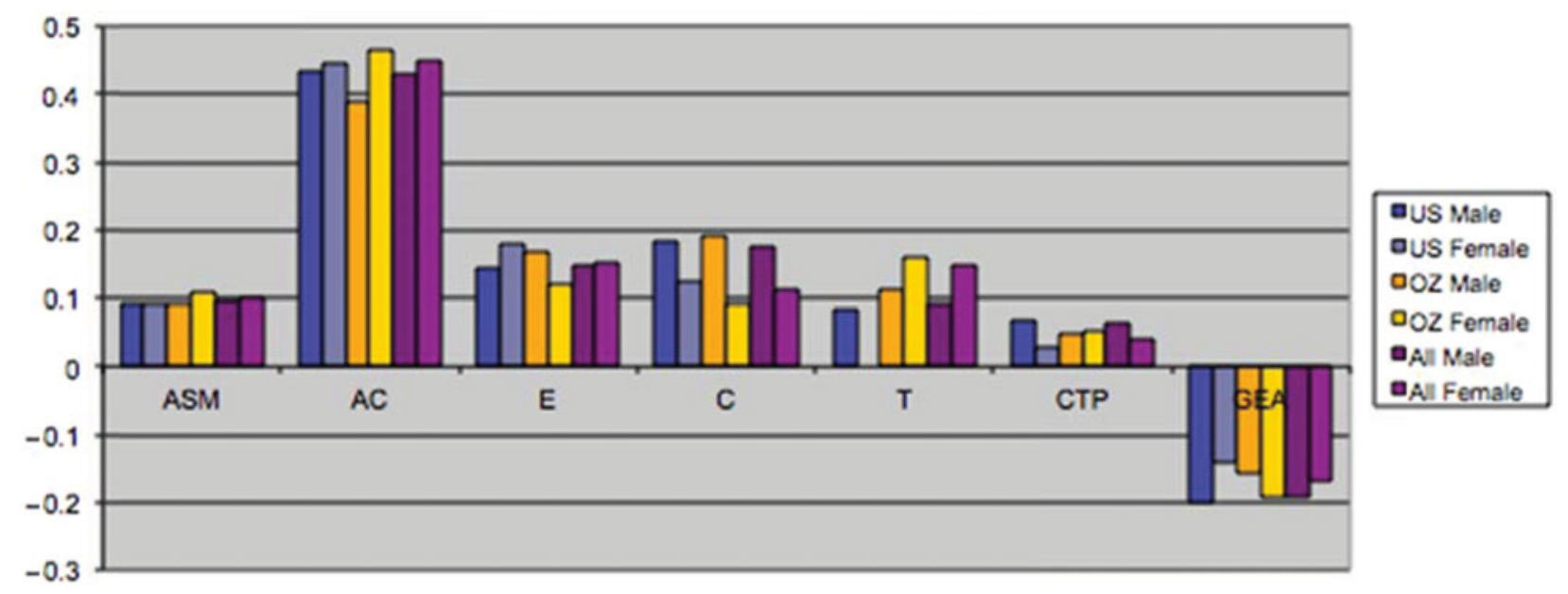

\section{FIGURE 3}

(Colour online) Continued

female non-parental shared environmental parameters and male-female shared environmental correlation) resulted in very comparable results across samples (see Table 3 ). Nonparental shared environment, special twin environment, and assortment could not be dropped without significant loss of fit. On the other hand, cultural transmission, additive genetic factors, or dominance factors by themselves could be dropped. However, test for overall genetic effects (additive and dominance; $\chi_{6}^{2}=85.6, p=.00$ ) or overall shared environmental effects (non-parental shared environment, special twin environment, and cultural transmission; $\chi_{10}^{2}=69.8, p=.00$ ) were highly significant, as was the test for familial resemblance $\left(\chi_{16}^{2}=1,654.9, p=.00\right)$. When dominance parameters were constrained to zero, and the male-female genetic ( $\mathrm{rd}$ and $\mathrm{rg}$ ) correlations were fixed to 1 (the latter by dropping the male-specific additive genetic parameters), results for the two samples were remarkably close. Furthermore, additive genetic factors and cultural transmission were then significant (see also Table 3).

Maximum likelihood estimates of the genetic and environmental parameters under the ET model and the derived proportions of variance for the genetic and environmental effects on SI from the analysis of individual observations of both samples combined are shown in Table 4 \& Figure 3. Additive genetic effects accounted for $53 \%$ of the variance in smoking in males and 55\% in females. These proportions included the effects due to assortative mating (about 10\%), consistent with the highly significant spousal correlation $r=0.40$. The contribution of genetic dominance was negligible. The shared environmental effects on 
TABLE 3

Model Fitting Results for Fitting the Extended Twin (ET) Model and Sub-models to Smoking Initiation in the U.S. and Australian Samples

\begin{tabular}{|c|c|c|c|c|c|c|c|}
\hline & \multirow[b]{2}{*}{$d f$} & \multicolumn{2}{|c|}{ U.S. } & \multicolumn{2}{|c|}{$\mathrm{OZ}$} & \multicolumn{2}{|c|}{ All } \\
\hline & & $x^{2}$ & $p$ & $x^{2}$ & $p$ & $x^{2}$ & $p$ \\
\hline \multicolumn{8}{|l|}{ Full ET model } \\
\hline No assortment & 1 & 249.1 & 0 & 368.0 & 0 & 506.0 & 0 \\
\hline No non-parental shared environment & 3 & 25.5 & 0 & 29.4 & 0 & 53.7 & 0 \\
\hline No special twin environment & 3 & 19.0 & 0 & 21.8 & 0 & 38.9 & 0 \\
\hline No cultural transmission & 4 & 5.1 & .27 & 0.8 & .94 & 2.6 & .62 \\
\hline No additive genetic effects & 3 & 6.2 & .10 & 1.8 & .61 & 7.5 & .06 \\
\hline No dominance effects & 3 & 0.2 & .98 & 2.4 & .50 & 1.9 & 6 \\
\hline No shared environment (cult tr $+\mathrm{np}$ env) & 10 & 69.8 & 0 & 63.5 & 0 & 126.3 & 0 \\
\hline No genetic effects & 6 & 85.6 & 0 & 82.5 & 0 & 165.7 & 0 \\
\hline No familial resemblance & 16 & 1654.9 & 0 & 1599.7 & 0 & 3240.8 & 0 \\
\hline \multicolumn{8}{|c|}{ ET without dominance and male-specific genetic factors (rg correlation) } \\
\hline No assortment & 1 & 247.6 & 0 & 257.3 & 0 & 504.1 & 0 \\
\hline No non-parental shared environment & 3 & 25.3 & 0 & 28.6 & 0 & 52.7 & 0 \\
\hline No special twin environment & 3 & 19.4 & 0 & 23.4 & 0 & 40.8 & 0 \\
\hline No cultural transmission & 4 & 13.0 & .01 & 6.0 & .20 & 14.1 & .01 \\
\hline No shared environment (cult tr $+\mathrm{np}$ env) & 10 & 183.0 & 0 & 206.9 & 0 & 380.9 & 0 \\
\hline No additive genetic effects & 3 & 85.4 & 0 & 80.2 & 0 & 163.8 & 0 \\
\hline No familial resemblance & 14 & 1654.7 & 0 & 1597.3 & 0 & 3238.9 & 0 \\
\hline
\end{tabular}

TABLE 4

Parameter Estimates and Variance Components from the ET Model for Smoking Initiation

\begin{tabular}{|c|c|c|c|c|c|c|c|c|c|c|}
\hline & \multicolumn{5}{|c|}{ Full ET } & \multirow{2}{*}{\multicolumn{3}{|c|}{$\frac{\text { No dominance }}{\text { Parameter estimates }}$}} & \multirow{2}{*}{\multicolumn{2}{|c|}{ Variance components }} \\
\hline & \multicolumn{3}{|c|}{ Parameter estimates } & \multicolumn{2}{|c|}{ Variance components } & & & & & \\
\hline & Male & Female & MF & Male & Female & Male & Female & MF & Male & Female \\
\hline Assortative mating & & & 0.40 & 0.01 & 0.05 & & & 0.40 & 0.10 & 0.10 \\
\hline Common additive genetic & 0.26 & 0.73 & & 0.06 & 0.50 & 0.73 & 0.74 & & 0.43 & 0.45 \\
\hline Male-specific genetic & 0.69 & & & 0.47 & & - & & & - & \\
\hline Dominance & 0.15 & -0.12 & 1 & 0.02 & 0.01 & - & - & - & - & - \\
\hline Unique environment & 0.45 & 0.44 & & 0.17 & 0.17 & 0.51 & 0.48 & & 0.15 & 0.15 \\
\hline Shared environment & 0.43 & 0.33 & 1 & 0.17 & 0.10 & 0.47 & 0.37 & 0.20 & 0.18 & 0.11 \\
\hline Twin environment & 0.28 & 0.41 & 0.99 & 0.07 & 0.16 & 0.33 & 0.42 & 0.74 & 0.09 & 0.15 \\
\hline Cultural transmission father & -0.18 & 0.01 & & 0.02 & 0.01 & -0.13 & -0.32 & & 0.06 & 0.04 \\
\hline Cultural transmission mother & -0.18 & -0.24 & & & & -0.48 & -0.23 & & & \\
\hline GE covariance & -0.14 & -0.10 & & & & -0.32 & -0.29 & & & \\
\hline GE covariance male-specific & -0.10 & -0.04 & & & & - & & & - & \\
\hline
\end{tabular}

smoking arose from non-parental sources, special twin environment, and cultural transmission. In males, these sources explained $17 \%, 9 \%$, and $6 \%$ of the variance, respectively. The corresponding proportions for females were $11 \%, 15 \%$, and $4 \%$. Genotype-environment covariance was estimated to be negative for males and females, which would result in negative contribution of this source of variance, if included in the calculation of variance components. Individual specific environmental factors made up the remainder of the variance ( $15 \%$ in males and females). The correlations between the non-parental and twin shared environments in males and females were estimated at 0.20 and 0.74, respectively, suggesting that partly different shared environmental factors account for similarity in SI in males and females. This is not surprising, since the opposite-sex twin and sibling correlations are considerably lower than their respective same-sex correlations. Given the large number of estimated parameters and the ordinal data input, estimating confidence intervals in OpenMx using the method of Neale and Miller (1997) would require an impractical amount of computer time. Therefore, we opted to fit a range of submodels, which allows us to test the significance of individual parameters or a group of parameters simultaneously (see Table 3).

\section{Discussion}

To our knowledge, the combined U.S. and Australian samples comprising 50,318 adult individuals from 88 distinct biological and social relationships constitute the largest and most informative study of the inheritance of SI to date. Our results add considerable weight to previous findings that genetic factors contribute significantly to family resemblance in SI. The overall contribution of genetic factors to individual differences was similar for females and males (broad heritability 55\%), consistent with previous large twin and 
family studies (Madden et al., 2004). However, in contrast with these previous studies, we have explicitly modeled the effects of assortative mating and environmental transmission, as both the design and the power allow us to detect more complex patterns of causation, if they exist (Eaves et al., 1977, 1989; Fulker, 1988; Heath \& Eaves, 1985; Heath et al., 1985; Martin et al., 1978). As such, the analyses of the Australian sample constitutes a replication of the results of the U.S. sample alone (Maes et al., 2006), which was formally tested by analyzing both samples simultaneously and testing the equality of the familial parameters. Most remarkably, the estimates of the 88 unique correlations in the Australian sample were very close to those in the U.S. sample, and consequently, the estimates of the genetic and environmental parameters were extremely close.

Results for the ET kinship analyses demonstrated not only that genetic factors play a significant role in the liability to SI, they also confirmed the role of assortative mating, shared sibling environment, twin environment (which could mask gene $\times$ age interaction), cultural transmission, and resulting genotype-environment covariance on individual differences in SI. The overall heritability in the combined data was estimated to be $55 \%$ in males and females. Note that this estimate of heritability is lower than in Maes et al. (2006) as it is calculated here as the proportion of variance, not including the (negative) genotype-environment (GE) covariance, such that all the variance components except for GE covariance add up to 1 . This provides a better comparison with other twin studies that cannot distinguish GE covariance. The combined U.S.-Australian heritability estimate was very close to the unweighted mean ( $56 \%$ for males, $50 \%$ for females) calculated from published reports on adult Scandinavian, Australian, and U.S. samples (Prescott et al., 2005). Note that the U.S. samples are mostly overlapping with the Virginia 30,000. The estimates of the specific environmental variance, including measurement error, were consistent across the current analyses (15\%) and published reports (18\%).

If substantial assortment exists for the phenotype of interest, the estimates of the genetic and environmental parameters from twin studies will be biased if assortment is not taken into account. The spousal correlation was estimated at 0.38 in the U.S. sample and 0.42 in the Australian sample, respectively, both of which are in line with published spousal correlations for SI, which range mostly from 0.18 to 0.43 , based on U.S., Swedish, Dutch, and Finnish samples (Boomsma et al., 1994; Kaprio et al., 1995; Price \& Vandenberg, 1980). Thus, results from the Australian sample confirmed that about $10 \%$ of the total variance in SI was due to the genetic consequences of assortative mating.

Twin studies have consistently reported significant contributions of the shared environment to the liability to SI, the unweighted mean from published reports of adult samples being 24-28\%. The U.S. and Australian samples both suggested that $30-35 \%$ of the variance can be accounted for by the combined effects of all sources of shared environment (sibling, twin, and cultural transmission), which is not far from previous estimates. The advantage of the extended kinship design is that it allows us to distinguish between the environmental effects shared with co-twins, siblings, and peers versus those shared with their parents. The results from the analysis of the Australian data confirmed significant contributions of non-parental shared environment (factors shared with siblings, and possibly additional factors shared with co-twins) and of cultural transmission observed in the U.S. sample, with similar proportions of variance accounted for by each source. The additional similarity in twins could be due to lingering effects of the intrauterine environment or greater socialization with people of similar age. In both samples, the shared environmental variance component was greater in males, and the special twin environmental component slightly greater in females. Furthermore, it appeared that the shared environmental factors were different in males and females in both samples, indicated by the significantly lower opposite sex versus same sex correlations. This observation is in line with previously reported correlations between the shared environmental factors of males and females $\left(r_{\mathrm{c}}\right)$ less than 1 for SI (Boomsma et al., 1994; Heath et al., 1993, Maes et al., 2017). However, it is also consistent with different sets of genes expressed in males and females, supported by the significant estimate of the male-specific genetic effects.

The finding of borderline significant contributions of parental shared environmental factors (or cultural transmission) was replicated in the Australian data, and they accounted for a similarly small proportion of the total variance (around 5\%) as in the U.S. data. Furthermore, the paths from parents to children's environment were also estimated to be negative, suggesting that parents have inhibiting or promoting effects on their children's SI. These results are consistent with the only other available twin-parent data, which also showed negative, but non-significant, cultural transmission (Boomsma et al., 1994). In fact, these results are also consistent with the vast epidemiological literature on parental smoking as a risk factor for adolescent smoking (Li et al., 2002; Peterson et al., 2005; Shakib et al., 2003; Vitaro et al., 2004) and parental non-smoking or smoking cessation as a protective factor (Andersen et al., 2004; Bricker et al., 2005; den Exter Blokland et al., 2004), derived from the moderate phenotypic correlations between parents and children or adolescents. Based on the heritability estimates from twin studies, parent-offspring correlations would be expected to be larger than they are. A possible explanation is that the environmental transmission is negative, while the genetic transmission is positive. Thus, the availability of a genetically informative design, with different types of relatives, is more informative than a nuclear family design, which does not allow for the separation of the genetic effects of parents on their children from the environmental influences. Furthermore, the marginal significance of 
cultural transmission compared to the non-parental shared environmental sources of variance corresponds to the finding that adolescent smoking is more strongly associated with friends' and siblings' smoking than parents' smoking (de Vries et al., 2003; Rose et al., 2003; Simons-Morton et al., 2004, Vink, Willemsen, \& Boomsma, 2003; Vink, Willemsen, Engels et al., 2003). Thus, it appears that the environmental impact on SI is age dependent, such that the influence of the parents on their offspring SI is limited and the observed parent-child association is primarily accounted for by shared genes.

Other possible genetic explanations for the lower than expected parent-offspring than sibling correlations are genetic dominance or gene $x$ age interaction. Unlike the classical twin study, the ET kinship design allows us to disentangle the combined effects of additive genetic, dominance, and shared environmental factors. The results from fitting the full model showed no evidence for dominance. In effect, the dominance variance was estimated very close to zero in both samples. The alternative explanation of gene $x$ age interaction implies that the genetic variance changes as a function of age and/or that different genes account for variability at different ages (Eaves et al., 1978), sometimes called reduced genetic transmission. Although the study was cross-sectional, we previously examined the change in genetic variance with age in two ways in the Virginia sample and concluded that the impact of age on the genetic architecture of SI is limited (Maes et al., 2006). Madden et al. (2004) also reported no change in additive genetic variance across three age groups between age 18 and 46, as well as three countries (Australia, Sweden, and Finland), in women and in men. The issue of gene $x$ age interaction could be further explored by moderating the correlation between relatives of different ages by their age difference (Verhulst et al., 2014).

On the other hand, age significantly influenced the prevalence of SI in males in the U.S. sample, but the effect was not significant for females or for either sex in the Australian sample. Given the estimates of genetic and environmental parameters would be slightly biased if ignored, age regression on the prevalence was modeled. However, cohort and age effects may be confounded. Although prevalence of tobacco use has decreased in both males and females since the data were collected, the estimates of the contribution of genetic and environmental factors are consistent with estimates from more recently collected samples. Given the prevalence of smoking decreased more rapidly with age in the cohorts captured in the Virginia 30,000 and the Australian 25,000 sample than data collected since then, results are expected to be influenced only to a limited extent.

In summary, the data on a wide range of biological and social relationships from two large samples on different continents confirmed that genetic factors accounted for the majority of individual differences in liability to SI, with a small proportion resulting from the consequences of assor- tative mating. Shared environmental factors do play a significant role, but were primarily due to within-generational influences; for example, siblings and co-twins. The association between SI in parents and their children could be most likely accounted for by their genetic relatedness, with limited negative environmental influence. It is important to note that the estimates obtained here were not just based on twin data, but on a wide range of relatives with different degrees of genetic similarity and shared environments. Furthermore, our estimates were obtained from taking the effects of sex, assortment, genotype $\times$ environment covariance, and age regression of the prevalence into account.

\section{Limitations}

Given the complexity of the model and the large number of estimated parameters, caution is needed in the interpretation of the results. Even with two large samples, information may be limited to estimate some parameters, especially those that are highly correlated or only identified by one or a few relationships. Second, the sample was entirely Caucasian, and we do not know whether the pattern of results holds for other ethnic groups. Third, the sample of twins and relatives is a volunteer sample, thus, the possibility of response bias exists. Response bias is principally a concern if missingness is related to the response variable (Little \& Rubin, 1987) and with relatives we are in the fortunate situation that we have information about non-responding relatives through the relatives who did respond (Neale \& Eaves, 1993). The fortunate consequence of maximum likelihood estimation with single relatives jointly with complete pairs is to correct the bias in mean and variance of the former toward their true population values (Little \& Rubin, 1987; Muthén et al., 1987).

\section{Acknowledgments}

This research has been supported by Grants AG04954, GM30250, GM32732, AA06781, AA07728, AA07535, and MH40828 from NIH, Grants 941177 and 971232 from the NH\&MRC, a gift from R.J.R. Nabisco and grants from the JM Templeton Foundation. The authors would also like to thank the twins and their families on both continents for their participation in this project. Hermine H. Maes is supported by Grants HL60688, MH45268, DA016977, MH068521, DA018673, DA025109, DA030005 and the Virginia Tobacco Youth Project.

\section{References}

Andersen, M. R., Leroux, B. G., Bricker, J. B., Rajan, K. B., \& Peterson, A. V. Jr. (2004). Antismoking parenting practices are associated with reduced rates of adolescent smoking. Archives of Pediatrics and Adolescent Medicine, 158, 348352.

Boker, S., Neale, M. C., Maes, H. H., Wilde, M., Spiegel, M., Brick, T., ... Fox, J. (2010). OpenMx: An open source 
extended structural equation modeling framework. Psychometrika, 76, 306-317.

Boomsma, D. I., Koopmans, J. R., Van Doornen, L. J., \& Orlebeke, J. F. (1994). Genetic and social influences of starting to smoke: A study of Dutch adolescent twins and their parents. Addiction, 89, 219-226.

Bricker, J. B., Rajan, K. B., Andersen, M. R., \& Peterson, A. V. Jr. (2005). Does parental smoking cessation encourage their young adult children to quit smoking? A prospective study. Addiction, 100, 379-386.

de Vries, H., Engels, R., Kremers, S., Wetzels, J., \& Mudde, A. (2003). Parents' and friends' smoking status as predictors of smoking onset: Findings from six European countries. Health Education Research, 18, 627-636.

den Exter Blokland, E. A., Engels, R. C., Hale, W. W., Meeus, W., \& Willemsen, M. C. (2004). Lifetime parental smoking history and cessation and early adolescent smoking behavior. Preventive Medicine, 38, 359-368.

Eaves, L. J., \& Eysenck, H. J. (1980). The causes and effects of smoking. London, UK: Maurice Temple Smith.

Eaves, L. J., Eysenck, H. J., \& Martin, N. G. (1989). Genes, culture and personality: An empirical approach. London, UK: Oxford University Press.

Eaves, L. J., Heath, A. C., Martin, N. G., Neale, M. C., Meyer, J. M., Silberg, J. L., ... Walters, E. (1999). Comparing the biological and cultural inheritance of stature and conservatism in the kinships of monozygotic and dizygotic twins. In C. R. Cloninger (Ed.), Proceedings of 1994 APPA Conference (pp. 269-308). Washington, DC: American Psychiatric Press.

Eaves, L. J., Last, K. A., Young, P. A., \& Martin, N. G. (1978). Model-fitting approaches to the analysis of human behaviour. Heredity, 41, 249-320.

Eaves, L. J., Last, K., Martin, N. G., \& Jinks, J. L. (1977). A progressive approach to non-additivity and genotypeenvironmental covariance in the analysis of human differences. British Journal of Mathematical and Statistical Psychology, 30, 1-42.

Fulker, D. W. (1988). Genetic and cultural transmission in human behavior. In S. B. Weir, E. J. Eisen, M. M. Goodman, \& G. Namkoong (Eds.), Proceedings of the 2nd International Conference on Quantitative Genetics (pp. 318-340). Sunderland, MA: Sinaver Associates.

Heath, A. C., Cates, R., Martin, N. G., Meyer, J., Hewitt, J. K., Neale, M. C., \& Eaves, L. J. (1993). Genetic contribution to risk of smoking initiation: Comparisons across birth cohorts and across cultures. Journal of Substance Abuse, 5, 221-246.

Heath, A. C., \& Eaves, L. J. (1985). Resolving the effects of phenotype and social background on mate selection. Behavior Genetics, 15, 15-30.

Heath, A. C., Kendler, K. S., Eaves, L. J., \& Markell, D. (1985). The resolution of cultural and biological inheritance: Informativeness of different relationships. Behavior Genetics, 15, 439-465.

Heath, A. C., Madden, P. A., \& Martin, N. G. (1998). Statistical methods in genetic research on smoking. Statistical Methods in Medical Research, 7, 165-186.
Heath, A. C., \& Martin, N.G. (1994). Genetic influences on alcohol consumption patterns and problem drinking: results from the Australian NH\&MRC twin panel follow-up survey. Ann N Y Acad Sci, 708: 72-85.

Jardine, R., Martin, N. G., \& Henderson, A. S. (1984). Genetic covariation between neuroticism and the symptoms of anxiety and depression. Genetic Epidemiology, 1, 89-107.

Kaprio, J. (2009). Genetic epidemiology of smoking behavior and nicotine dependence. Journal of Chronic Obstructive Pulmonary Disease, 6, 304-306.

Kaprio, J., Boomsma, D. I., Heikkilä, K., Koskenvuo, M., Romanov, K., Rose, R. J., ... Winter, T. (1995). Genetic variation in behavioral risk factors for atherosclerosis: Twinfamily study of smoking and cynical hostility. In F. P. Woodford, J. Davignon \& A. Sniderman (Eds.), Proceedings of the 10th International Symposium on Atherosclerosis, Montreal, 1994. Vol. 1066 (pp. 63-637). New York, NY: Elsevier.

Kendler, K. S., Karkowski, L. M., \& Pedersen, N. C. (2000). Tobacco consumption in Swedish twins reared-apart and reared-together. Archives of General Psychiatry, 57, 886892.

Lake, R. I. E., Eaves, L. J., Maes, H. H. M., Heath, A. C., \& Martin, N. G. (2000). Further evidence against the environmental transmission of individual differences in neuroticism from a collaborative study of 45,850 twins and relatives on two continents. Behavior Genetics, 30, 223-233.

Li, C., Pentz, M. A., \& Chou, C. P. (2002). Parental substance use as a modifier of adolescent substance use risk. Addiction, 97, 1537-1550.

Li, M. D. (2003). The genetics of smoking related behavior: A brief review. American Journal of the Medical Sciences, 326, 168-173.

Little, R. J. A., \& Rubin, D. B. (1987). Statistical analysis with missing data. New York, NY: John Wiley \& Sons.

Madden, P. A., Pedersen, N. L., Kaprio, J., Koskenvuo, M. J., \& Martin, N. G. (2004). The epidemiology and genetics of smoking initiation and persistence: Cross-cultural comparisons of twin study results. Twin Research, 7, 82-97.

Maes, H. H., \& Neale, M. C. (2009). Genetic modeling of tobacco use behavior and trajectories. In G. Swan, T. Baker, I. Chassin, D. Conti, C. Lerman \& K. Perkins (Eds.), NCI tobacco control monograph series 20: Phenotypes and endophenotypes: Foundations for genetic studies of nicotine use and dependence. Bethseda, MD: US Department of Health and Human Services, National Institutes of Health.

Maes, H. H., Neale, M. C., Kendler, K. S., Martin, N. G., Heath, A. C., \& Eaves, L. J. (2006). Genetic and cultural transmission of smoking initiation. An extended twin kinship model. Behavior Genetics, 36, 795-808.

Maes, H. H., Neale, M. C., Martin, N. G., Heath, A. C., \& Eaves, L. J. (1999). Religious attendance and frequency of alcohol use: Same genes or same environments: A bivariate extended twin kinship model. Twin Research, 2, 169-179.

Maes, H. H., Prom-Wormley, E., Eaves, L. J., Rhee, S. H., Hewitt, J. K., Young, S., Corley, R., McGue, M., Iacono, W. G., Legrand, L., Samek, D. R., Murrelle, E. L., Silberg, J. L., Miles, D. R., Schieken, R. M., Beunen, G. P., 
Thomis, M., Rose, R. J., Dick, D. M., Boomsma, D. I., Bartels, M., Vink, J. M., Lichtenstein, P., White, V., Kaprio, J., \& Neale, M. C. (2017). A Genetic Epidemiological Mega Analysis of Smoking Initiation in Adolescents. Nicotine Tob Res, 19: 401-409.

Martin, N. G., Eaves, L. J., Kearsey, M. J., \& Davies, P. (1978). The power of the classical twin study. Heredity, 40, 97-116.

Martin, N. G., \& Martin, P. G. (1975). The inheritance of scholastic abilities in a sample of twins. I. Ascertainment of the sample and diagnosis of zygosity. Annals of Human Genetics, 39, 213-218.

Muthén, B., Kaplan, D., \& Hollis, M. (1987). On structural equation modeling with data that are not missing completely at random. Psychometrika, 52, 431-462.

Neale, M. C., Boker, S. M., Xie, G., \& Maes, H. H. (2006). Mx: Statistical modeling (7th ed.). Richmond, VA: Department of Psychiatry, Virginia Commonwealth University.

Neale, M. C., \& Cardon, L. R. (1992). Methodology for genetic studies of twins and families. Dortrecht, Germany: Kluwer Academic Publishers.

Neale, M. C., \& Eaves, L. J. (1993). Estimating and controlling for the effects of volunteer bias with pairs of relatives. Behavior Genetics, 23, 271-277.

Neale, M. C., Hunter, M. D., Pritikin, J. N., Zahery, M., Brick, T. R., Kirkpatrick, R. M., ... Boker, S. M. (2017). OpenMx 2.0: Extended structural equation and statistical modeling. Psychometrika, 81, 535-549.

Neale, M. C., \& Miller, M. B. (1997). The use of likelihoodbased confidence intervals in genetic models. Behavior Genetics, 27, 113-120.

Ooki, S., Yamada, K., Asaka, A., \& Hayakawa, K. (1990). Zygosity diagnosis of twins by questionnaire. Acta Geneticae Medicae et Gemellologiae (Roma), 39, 109-115.

Peterson, A. V. Jr., Leroux, B. G., Bricker, J., Kealey, K. A., Marek, P. M., Sarason, I. G., \& Andersen, M. R. (2005). Nine-year prediction of adolescent smoking by number of smoking parents. Addictive Behaviors, 31, 788801

Prescott, C. A., Maes, H. H., \& Kendler, K. S. (2005). Genetics of substance use disorders. In K. S. Kendler \& L. J. Eaves (Eds.), Psychiatric genetics. Review of psychiatry, vol. 24 (pp. 167-196). Washington, DC: American Psychiatric Publishing.

Price, R. A., \& Vandenberg, S. G. (1980). Spouse similarity in American and Swedish couples. Behavior Genetics, 10, 5971 .
Rose, R. J., Viken, R. J., Dick, D. M., Bates, J. E., Pulkkinen, L., \& Kaprio, J. (2003). It does take a village: Nonfamilial environments and children's behavior. Psychological Science, 14, 273-277

Scollo, M. M., \& Winstanley, M. H. (2015). Tobacco in Australia: Facts and issues. Melbourne, Australia: Cancer Council Victoria.

Shakib, S., Mouttapa, M., Johnson, C. A., Ritt-Olson, A., Trinidad, D. R., Gallaher, P. E., \& Unger, J. B. (2003). Ethnic variation in parenting characteristics and adolescent smoking. Journal of Adolescent Health, 33, 88-97.

Simons-Morton, B., Chen, R., Abroms, L., \& Haynie, D. L. (2004). Latent growth curve analyses of peer and parent influences on smoking progression among early adolescents. Health Psychology, 23, 612-621.

Sullivan, P. F., \& Kendler, K. S. (1997). The genetic epidemiology of smoking. Nicotine \& Tobacco Research, 1, S51-S57.

Truett, K. R., Eaves, L. J., Walters, E. E., Heath, A. C., Hewitt, J. K., Meyer, J. M., ... Kendler, K. S. (1994). A model system for analysis of family resemblance in extended kinships of twins. Behavior Genetics, 24, 35-49.

U.S. Department of Health and Human Services. (2010). How tobacco smoke causes disease: The biology and behavioral basis for smoking-attributable disease: A report of the Surgeon General. Atlanta, GA: U.S. Department of Health and Human Services, Centers for Disease Control and Prevention, National Center for Chronic Disease Prevention and Health Promotion, Office on Smoking and Health.

Verhulst, B., Eaves, L. J., \& Neale, M. C. (2014). Moderating the covariance between family member's substance use behavior. Behavior Genetics, 44, 337-346.

Vink, J. M., Willemsen, G., \& Boomsma, D. I. (2003). The association of current smoking behavior with the smoking behavior of parents, siblings, friends and spouses. Addiction, 98, 923-931.

Vink, J. M., Willemsen, G., Engels, R. C., \& Boomsma, D. I. (2003). Smoking status of parents, siblings and friends: Predictors of regular smoking? Findings from a longitudinal twin-family study. Twin Research, 6, 209-217.

Vitaro, F., Wannera, B., Brendgena, M., Gosselinb, C., \& Gendreaua, P. L. (2004). Differential contribution of parents and friends to smoking trajectories during adolescence. Addictive Behaviors, 29, 831-835

World Health Organization. (2018). Tobacco fact sheet. Retrieved from http://www.who.int/mediacentre/factsheets/ fs $339 /$ en/ 